\title{
Upgrading the Properties of Reduced Graphene Oxide and Nitrogen-Doped Reduced Graphene Oxide Produced by Thermal Reduction toward Efficient ORR Electrocatalysts
}

\author{
Carolina S. Ramirez-Barria ${ }^{1,2}$, Diana M. Fernandes ${ }^{3, *}$, Cristina Freire ${ }^{3}{ }^{\circledR}$, Elvira Villaro-Abalos ${ }^{4}$, \\ Antonio Guerrero-Ruiz $2, *(1)$ and Inmaculada Rodríguez-Ramos $1, *($ ) \\ 1 Instituto de Catálisis y Petroleoquímica, CSIC, Marie Curie 2, 28049 Madrid, Spain; \\ ramirez.carolina@outlook.com \\ 2 Dpto. Química Inorgánica y Técnica, Facultad de Ciencias UNED, Senda del Rey 9, 28040 Madrid, Spain \\ 3 REQUIMTE/LAQV, Departamento de Química e Bioquímica, Faculdade de Ciências, Universidade do Porto, \\ 4169-007 Porto, Portugal; acfreire@fc.up.pt \\ 4 Interquimica, Antonio de Nebrija 8, 26006 Logroño, Spain; evillaro@interquimica.org \\ * Correspondence: diana.fernandes@fc.up.pt (D.M.F.); aguerrero@ccia.uned.es (A.G.-R.); \\ irodriguez@icp.csic.es (I.R.-R.); Tel.: +34-915854765 (I.R.-R.)
}

Received: 21 November 2019; Accepted: 9 December 2019; Published: 11 December 2019

check for updates

\begin{abstract}
N}$-doped ( $\mathrm{NrGO}$ ) and non-doped (rGO) graphenic materials are prepared by oxidation and further thermal treatment under ammonia and inert atmospheres, respectively, of natural graphites of different particle sizes. An extensive characterization of graphene materials points out that the physical properties of synthesized materials, as well as the nitrogen species introduced, depend on the particle size of the starting graphite, the reduction atmospheres, and the temperature conditions used during the exfoliation treatment. These findings indicate that it is possible to tailor properties of non-doped and N-doped reduced graphene oxide, such as the number of layers, surface area, and nitrogen content, by using a simple strategy based on selecting adequate graphite sizes and convenient experimental conditions during thermal exfoliation. Additionally, the graphenic materials are successfully applied as electrocatalysts for the demanding oxygen reduction reaction (ORR). Nitrogen doping together with the starting graphite of smaller particle size $\left(\mathrm{NrGO}_{325}-4\right)$ resulted in a more efficient ORR electrocatalyst with more positive onset potentials ( $E_{\text {onset }}=0.82 \mathrm{~V}$ versus RHE), superior diffusion-limiting current density $\left(j_{\mathrm{L}}, 0.26 \mathrm{~V}, 1600 \mathrm{rpm}=-4.05 \mathrm{~mA} \mathrm{~cm}^{-2}\right)$, and selectivity to the direct four-electron pathway. Moreover, all $\mathrm{NrGO}_{\mathrm{m}}-4$ show high tolerance to methanol poisoning in comparison with the state-of-the-art ORR electrocatalyst $\mathrm{Pt} / \mathrm{C}$ and good stability.
\end{abstract}

Keywords: graphite; reduced graphene oxide; nitrogen-doped reduced graphene oxide; exfoliation; oxygen reduction reaction; electrocatalysis

\section{Introduction}

In recent years, the interest in graphene has grown due to its many outstanding electronic, thermal, chemical, and mechanical properties [1]. These properties give graphene an enormous versatility. It can be extensively used in diverse applications including energy conversion and storage technologies [2-5], electronics [6], and sensing device applications [7]. Graphenic materials have also been widely employed as solid (electro)catalytic materials, either as active phases or as supports [8]. These (electro)catalytic applications strongly depend on its surface chemical properties. It is well known that the surface chemical properties of graphenic materials can be tuned by covalent added 
adatoms [9]. Thus, the presence of nitrogen or boron atoms in the basal planes of graphene layers produce changes to many of their chemical properties. It was proven that the doping of nitrogen into a graphenic nanostructure modifies its chemical and electrical properties, [10]. Thus, the $\mathrm{N}$ atoms inserted in the graphene structure increase the electronic density of the graphenic layer, since one more electron is added to the graphenic layer, making it more basic [11,12]. In addition, the easily tunable surface chemical properties and specific surface area of the graphenic materials make them very versatile materials for application in this field.

An extensive number of works have been devoted to the preparation of graphene and $\mathrm{N}$-doped graphene. The synthesis of graphene can be performed using different methods, among them the micromechanical cleavage method [13], chemical vapor deposition (CVD) [14], and epitaxial growth on silicon carbide surfaces [15]. However, they show low productivity and lack of properties' selectivity. One of the common approaches used for a large-scale graphene production is based on the chemical oxidation of graphite $(\mathrm{G})$ flakes to produce graphite oxide (GO) $[16,17]$ with strong oxidizing agents. GO can be later exfoliated and converted to reduced graphene oxide (rGO) through a reduction procedure. The most used routes for the reduction of GO are chemical [18,19], electrochemical [20,21], solvothermal [22,23], and thermal treatments [24]. The use of thermal reduction is preferred over the rest of the methods due to its simplicity and industrial scalability [25].

The incorporation of nitrogen in graphenic materials to produce $\mathrm{N}$-doped reduced graphene oxide (NrGO) has been described using several methods as well. For example, CVD using $\mathrm{NH}_{3}$ [26], acetonitrile [27], or pyridine [28] as the N source; the arc discharge of graphite [29] in the presence of pyridine or $\mathrm{NH}_{3}$; the nitrogen plasma treatment of graphene [30]; and the thermal treatment of $\mathrm{GO}$ with melamine [31,32], urea [33], or $\mathrm{NH}_{3}$ [9,34].

The improvement of some of the properties of rGO and NrGO has been undertaken using different synthetic strategies. Wu et al. [35] studied a chemical exfoliation of GO to produce reduced graphene oxide with a selective number of layers based on different starting materials such as pyrolytic graphite, natural flake graphite, Kish graphite, flake graphite powder, and artificial graphite. They reported the effect of the lateral size and crystallinity of these starting graphite materials on the number of graphene layers presented in the obtained graphenic material. They found that graphite samples with a small lateral size and low crystallinity produce a higher proportion of single layer graphene. Li et al. [34] obtained NrGO through the thermal annealing of $\mathrm{GO}$ in $\mathrm{NH}_{3}$ sweeping temperatures between 300 and $1100{ }^{\circ} \mathrm{C}$. Annealing at $500{ }^{\circ} \mathrm{C}$ afforded the highest $\mathrm{N}$-doping level of $\sim 5 \%$, showing the strong influence of the temperature on the nitrogen content of the obtained materials. They claim that the N-doping degree depends on the amount of oxygen functional groups of graphene as they are responsible for the formation of $\mathrm{C}-\mathrm{N}$ bonds. The higher the annealing temperature is, the lower the content of oxygen, leading to a lower reactivity between the graphene layer and $\mathrm{NH}_{3}$. The production of $\mathrm{NrGO}$ based on the annealing of GO in the presence of melamine at high temperature $\left(700-1000{ }^{\circ} \mathrm{C}\right)$ has been reported by Sheng et al. [32]. They noted that nitrogen content depends on the mass ratio between GO and melamine as well as on the temperature, reaching values of 10.1 at \% using a 1:5 ratio of GO to melamine at $700{ }^{\circ} \mathrm{C}$. A similar approach was used by Canty et al. [33] working with urea and GO as precursor materials of NrGO. They used the ratio of GO to urea as a way to control the amount of nitrogen inserted and the surface area values obtained. Nonetheless, neither Li et al. [34] nor Canty et al. [33] reported a systematic study of the synthesis conditions to optimize NrGO properties. Menendez's group [25] analyzed the effect of the experimental conditions of the thermal transformation of GO onto $\mathrm{rGO}$, finding that the treatment temperature strongly affects the type and amount of functional groups obtained. Following this line of research, they proposed that the temperature of the initial flash thermal treatment allows the control of the surface area obtained [36]. However, the surface area values achieved were lower than $500 \mathrm{~m}^{2} \mathrm{~g}^{-1}$. Zhang et al. [37] proposed a vacuum-promoted thermal exfoliation method for different samples of GO, which were obtained from natural flake graphites with particle sizes ranging from 100 to 5000 mesh. Nevertheless, neither the morphology nor the structures of different graphenic samples were affected by the parent graphite particle size. The surface areas 
observed were around $490 \mathrm{~m}^{2} \mathrm{~g}^{-1}$ and the C/O ratio determined by XPS analysis revealed that all the samples had almost the same oxygen content. Thus, the vacuum-promoted exfoliation method minimizes the differences originated from the raw graphite particle size. The effect of the raw graphite size on the rGO properties has been also described by Dao et al. [38]. They prepared rGO by the rapid heating of dry GO using three graphite particle sizes obtained from grinding a large graphite sample. An increase in the surface area was observed as the particle size of the samples was reduced, reaching a value of $739 \mathrm{~m}^{2} \mathrm{~g}^{-1}$ in their best sample. This improvement was explained as being due to the better oxidation degree achieved with the decrease of the graphite particle size, which also favors a better exfoliation of the GO.

On the other hand, a previous study of our group [10] reported the synthesis of NrGO from GO obtained from three different graphite particle sizes. We found that the quantity of nitrogen and the surface properties obtained were dependent on the particle size of the graphite used. However, the surface areas obtained were not optimized enough.

Due to the lack of simultaneous and systematic reports regarding the combined effect of raw graphite size and the conditions of the thermal treatment (heating rate and temperature) on the properties of non-doped and $\mathrm{N}$-doped reduced graphene oxide, we have investigated the preparation of graphenic materials using three different particle sizes of starting graphite and using various thermal treatments. Moreover, a deep characterization of the graphenic materials was performed before applying those as electrocatalysts (ECs) for the oxygen reduction reaction, in order to optimize the properties of the obtained materials-particularly, the surface area and content of nitrogen-due to the importance of these parameters in their electrocatalytic performance. Finally, the synthesized materials have been tested as ECs in the oxygen reduction reaction (ORR).

\section{Materials and Methods}

\subsection{Preparation and Characterization of Graphenic Materials}

Graphenic materials were prepared by the treatment of graphite oxide (GO) at high temperature. Natural graphite powders of various grain sizes-10 mesh, 100 mesh, and 325 mesh (supplied by Alfa Aesar, Thermo Fisher Scientific, UK, purity 99.8\%) were used for the synthesis of GO through a modified Brodie's method [17]. This procedure consists of the addition of $10 \mathrm{~g}$ of graphite (G) over $200 \mathrm{~mL}$ of fuming $\mathrm{HNO}_{3}$, keeping the mixture at $0^{\circ} \mathrm{C}$. First, $80 \mathrm{~g}$ of $\mathrm{KClO}_{3}$ was gradually added over $2 \mathrm{~h}$. Afterward, the mixture was stirred for $21 \mathrm{~h}$, maintaining the $0^{\circ} \mathrm{C}$ temperature. The GO obtained was filtered and washed systematically with water until neutral $\mathrm{pH}$ and dried under vacuum at room temperature. The resultant samples were labeled $\mathrm{GO}_{\mathrm{m}}$, where $\mathrm{m}$ indicates the mesh size used.

The $\mathrm{GO}_{\mathrm{m}}$ were exfoliated in a vertical quartz reactor under two different atmospheres. The first atmosphere consists of nitrogen $\left(87 \mathrm{~mL} / \mathrm{min}\right.$ ) producing $\mathrm{rGO}$, while the second was a mixture of $\mathrm{NH}_{3}$, $\mathrm{H}_{2}$, and $\mathrm{N}_{2}(10,3$, and $87 \mathrm{~mL} / \mathrm{min}$, respectively) generating NrGO.

In order to study the effect of temperature and heating rate on the properties of rGO and $\mathrm{NrGO}$, for each atmosphere described, five different exfoliation ramps were applied over $\mathrm{GO}_{325}$. In a first ramp, $0.3 \mathrm{~g}$ of $\mathrm{GO}$ was introduced in the furnace and heated at $5^{\circ} \mathrm{C} \mathrm{min}^{-1}$ to $250{ }^{\circ} \mathrm{C}$; then, the sample was kept at this temperature for $30 \mathrm{~min}$. The temperature was increased from 250 to $500{ }^{\circ} \mathrm{C}$ with a heating rate of $5{ }^{\circ} \mathrm{C} \mathrm{min}^{-1}$ and then kept at this temperature for 30 minutes. In a second and third ramp, GO was heated at $5{ }^{\circ} \mathrm{C} \mathrm{min}^{-1}$ and $10^{\circ} \mathrm{C} / \mathrm{min}$ respectively to $250^{\circ} \mathrm{C}$; then, the sample was kept at this temperature for $30 \mathrm{~min}$. The temperature was increased from 250 to $700^{\circ} \mathrm{C}$ using the same heating rates, and then this temperature was maintained for $30 \mathrm{~min}$. In a fourth ramp, GO was heated at $5{ }^{\circ} \mathrm{C}$ $\min ^{-1}$ to $100^{\circ} \mathrm{C}$; then, the sample was kept at this temperature for $1 \mathrm{~h}$. The temperature was increased from 100 to $700{ }^{\circ} \mathrm{C}$ with a heating rate of $10^{\circ} \mathrm{C} \mathrm{min}^{-1}$; then, the sample was kept at this temperature for $5 \mathrm{~min}$. Finally, in the fifth ramp, the GO was heated up to $250{ }^{\circ} \mathrm{C}$ at $20^{\circ} \mathrm{C} \mathrm{min}-1$; then, the sample was kept at this temperature for $30 \mathrm{~min}$. The temperature was subsequently increased from 250 to $500{ }^{\circ} \mathrm{C}$ with a heating rate of $20^{\circ} \mathrm{C} \mathrm{min}^{-1}$; then, the sample was kept at this temperature for $30 \mathrm{~min}$. 
For the exfoliation of the samples $\mathrm{GO}_{10}$ and $\mathrm{GO}_{100}$, the temperature and heating rate used were selected according to the ramp that gave the higher value of surface area among the exfoliated samples of $\mathrm{GO}_{325}$. The samples obtained were labeled $\mathrm{rGO}_{\mathrm{m}}-\mathrm{r}$ and $\mathrm{NrGO}_{\mathrm{m}}-\mathrm{r}$, respectively, where $\mathrm{m}$ indicates the mesh size used and $r$ indicates the ramp used.

The characterization of the as-prepared materials was carried out by different techniques: elemental analysis, nitrogen adsorption isotherms, X-ray diffraction (XRD), scanning electron microscopy (SEM), transmission electron microscopy (TEM), and X-ray photoelectron spectroscopy (XPS). The detailed equipment and methods used are described in the electronic supporting information (ESI) file.

\subsection{ORR Electrocatalytic Activities}

For the cyclic voltammetry (CV) and linear sweep voltammetry (LSV) experiments, an Autolab PGSTAT 302N potentiostat/galvanostat (EcoChimie B.V. Netherlands) was used. A modified glassy carbon rotating disk electrode, $\mathrm{RDE}(d=3 \mathrm{~mm}$, Metrohm, Switzerland) was used as the working electrode, a carbon rod ( $d=2 \mathrm{~mm}$, Metrohm, Switzerland) was used as the counter, and an $\mathrm{Ag} / \mathrm{AgCl}$ ( $3 \mathrm{~mol} \mathrm{dm}{ }^{-3} \mathrm{KCl}$, Metrohm, Switzerland) was used as the reference electrode.

Before any type of modification, the electrode was cleaned (detailed information in ESI). The electrode modification was achieved by dropping $2 \times 2.5 \mu \mathrm{L}$ of electrocatalyst dispersion onto the RDE surface followed by solvent evaporation under a flux of hot air. To prepare the electrocatalyst dispersion, $1 \mathrm{mg}$ of material was mixed with $20 \mu \mathrm{L}$ of Nafion, $125 \mu \mathrm{L}$ of ultrapure water, and $125 \mu \mathrm{L}$ of isopropanol. Then, the mixture was sonicated for $15 \mathrm{~min}$.

The CV and LSV tests were performed in $\mathrm{KOH}$ electrolyte $\left(0.1 \mathrm{~mol} \mathrm{dm}{ }^{-3}\right)$ saturated in $\mathrm{O}_{2}$ and $\mathrm{N}_{2}$. (30 min purge for each gas). The potential range used for CV and LSV tests was between 0.26 and $1.46 \mathrm{~V}$ versus reversible hydrogen electrode (RHE) at a scan rate of $0.005 \mathrm{~V} \mathrm{~s}^{-1}$. In addition, for the LSV tests, rotation speeds between 400 and $3000 \mathrm{rpm}$ were used. The effective ORR current was determined through the subtraction of the current obtained in $\mathrm{KOH}$ saturated with $\mathrm{N}_{2}$ by that saturated with $\mathrm{O}_{2}$. The stability was evaluated by chronoamperometry (CA) for 20,000 s at $0.5 \mathrm{~V}$ versus RHE and $1600 \mathrm{rpm}$. CA was also used to determine the tolerance to methanol crossover by applying a $E=0.5 \mathrm{~V}$ versus RHE for $2000 \mathrm{~s}$ and a $1600 \mathrm{rpm}$ rotation speed.

All relevant ORR parameters (effective currents, diffusion-limiting current densities $\left(j_{\mathrm{L}}\right)$, onset potential $\left(E_{\text {onset }}\right)$, Tafel slope, and the number of electrons transferred for each $\mathrm{O}_{2}$ molecule $\left(\tilde{n}_{\mathrm{O} 2}\right)$ ) were calculated as described in the ESI file.

Experiments with the rotating ring disk electrode (RRDE) were also conducted in $\mathrm{KOH}$ electrolyte saturated with $\mathrm{O}_{2}$ to determine the amount of $\mathrm{H}_{2} \mathrm{O}_{2}$ produced. This was achieved using Equation (1) where $i_{\mathrm{R}}$ and $i_{\mathrm{D}}$ correspond to the ring and disk currents, respectively, and $\mathrm{N}$ is the current collection efficiency of the Pt ring $(N=0.25)$ [39].

$$
\% \mathrm{H}_{2} \mathrm{O}_{2}=200 \times \frac{i_{R} / N}{i_{D}+i_{R} / N}
$$

\section{Results and Discussion}

\subsection{Characteristics of the Graphenic Materials}

$\mathrm{XRD}$ is a powerful tool to evaluate the interlayer changes of graphene-based materials. The XRD patterns of $\mathrm{G}_{10}, \mathrm{G}_{100}, \mathrm{G}_{325}, \mathrm{GO}_{10}, \mathrm{GO}_{100}$, and $\mathrm{GO}_{325}$ samples are shown in Figure 1. The $\mathrm{G}$ samples presented the characteristic diffraction peak corresponding to pristine graphite (002) reflection at $2 \theta \sim 26^{\circ}[10]$. 


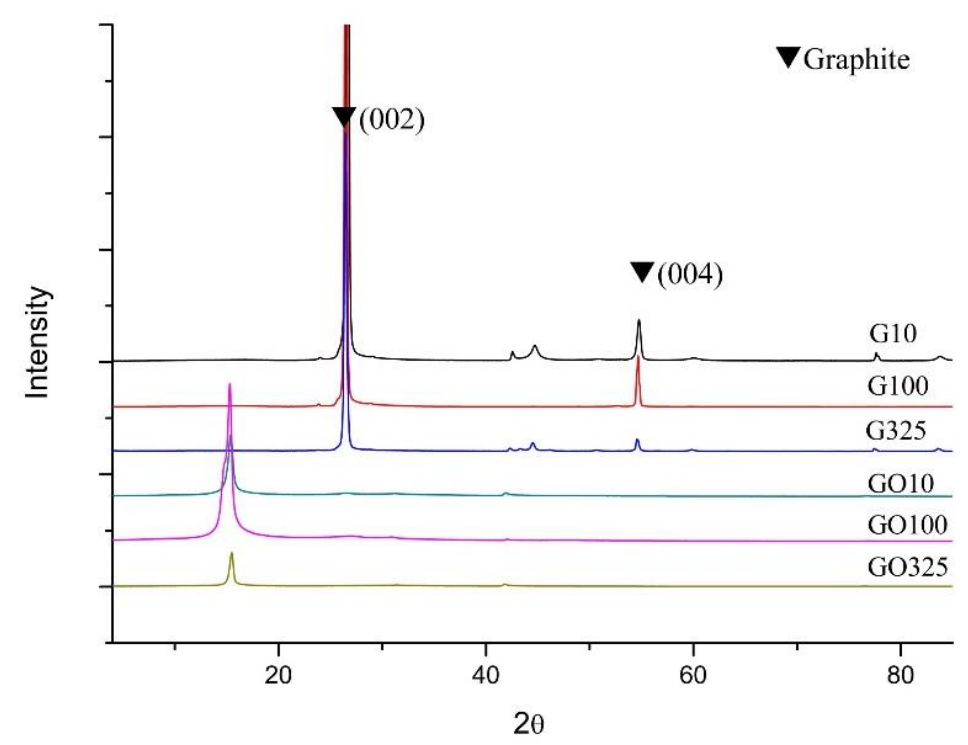

Figure 1. XRD patterns of graphene $\left(\mathrm{G}_{\mathrm{m}}\right)$ and graphite oxide $\left(\mathrm{GO}_{\mathrm{m}}\right)$, where $\mathrm{m}$ indicates the mesh samples used.

A downshift for (002) reflection peak to $2 \theta \sim 15^{\circ}$ after the oxidation treatment was observed for all the GO samples. It indicates that a successful oxidization of all $\mathrm{G}$ samples was achieved [8]. The distance between layers $\left(\mathrm{d}_{(002)}\right)$ increased from $0.33 \mathrm{~nm}$ (for $\left.\mathrm{G}\right)$ to $0.57 \mathrm{~nm}$ (for GO samples), which is due to the presence of interlayered species incorporated during the oxidation of graphite [25].

The morphology of the GOs was observed by SEM. Figure 2 shows representative images of the GO samples. The analysis of the particle size distribution based on a minimum of 200 particles shows that the average particle sizes of $\mathrm{GO}_{10}, \mathrm{GO}_{100}$, and $\mathrm{GO}_{325}$ samples are 86,38 , and $25 \mu \mathrm{m}$, respectively.

Slow heating rates were selected to be evaluated during the exfoliation process of GOs, since fast heating rates produce more wrinkled sheets [25]. Thus, small heating rates are fast enough to produce an effective expansion allowing the exfoliation and minimizing the distortion of the graphene sheets. It is known that oxygen groups decompose at high temperatures, reducing the number of reactive sites for $\mathrm{N}$ doping [34], and that high annealing temperatures $\left(>700^{\circ} \mathrm{C}\right)$ could break $\mathrm{C}-\mathrm{N}$ bonds in the NrGO materials leading to a low doping level [40]. So, temperatures up to $700{ }^{\circ} \mathrm{C}$ were used in the thermal treatments applied to the GO samples.

Table 1 compiles the main characteristics of the non-doped and $\mathrm{N}$-doped reduced graphite oxides obtained. Firstly, the $\mathrm{GO}_{325}$ sample was submitted in both inert atmosphere and atmosphere with the presence of ammonia to five different thermal ramps described in the experimental section. Application of the BET method to $\mathrm{N}_{2}$ adsorption isotherms (these type IV isotherms were displayed in the Figure S1 of the Electronic Supplementary Information, ESI) measured over the $\mathrm{GO}_{325}$-derived non-doped and $\mathrm{N}$-doped reduced graphene oxides gave surface area $\left(\mathrm{S}_{\mathrm{BET}}\right)$ values ranging from 667 to $867 \mathrm{~m}^{2} \mathrm{~g}^{-1}$ for the different $\mathrm{rGO}_{325}$ samples and from 427 to $492 \mathrm{~m}^{2} \mathrm{~g}^{-1}$ for the $\mathrm{NrGO}_{325}$ samples. These obtained $\mathrm{S}_{\mathrm{BET}}$ values are significantly lower than the theoretical value calculated for a single layer of graphene $\left(2630 \mathrm{~m}^{2} \mathrm{~g}^{-1}\right)$ [8]. This finding indicates the piling up of graphene layers and the formation of a few-layer graphene structure for both $\mathrm{rGO}$ and $\mathrm{NrGO}$. However, these values are much higher than the values previously reported using thermal exfoliation to produce $\mathrm{rGO}[36,38]$ and $\mathrm{NrGO}[10]$. From the results shown in Table 1, it can be seen that ramp 3 for non-doped reduced graphene oxide $\left(\mathrm{rGO}_{325}\right)$ and ramp 4 for $\mathrm{N}$-doped reduced graphene oxide $\left(\mathrm{NrGO}_{325}\right)$ led to reduced materials having an enhanced $\mathrm{S}_{\mathrm{BET}}$. The ramps used for the exfoliation of $\mathrm{GO}_{10}$ and $\mathrm{GO}_{100}$ were selected based on these results. Thus, the ramp used for the preparation of $\mathrm{rGO}_{10}$ and $\mathrm{rGO}_{100}$ was ramp 3, and for $\mathrm{NrGO}_{10}$ and $\mathrm{NrGO}_{100}$ was ramp 4. A significant and gradual decrease of the surface area values was observed for $\mathrm{rGO}$ and $\mathrm{NrGO}$ sample series as the size of starting graphite increases. These findings are coherent with the tendency 
previously reported for non-doped graphene by Dao et al. [38] where the lower the starting G size, the higher the oxidation degree of the obtained GO, which could lead to a better exfoliation of rGO.

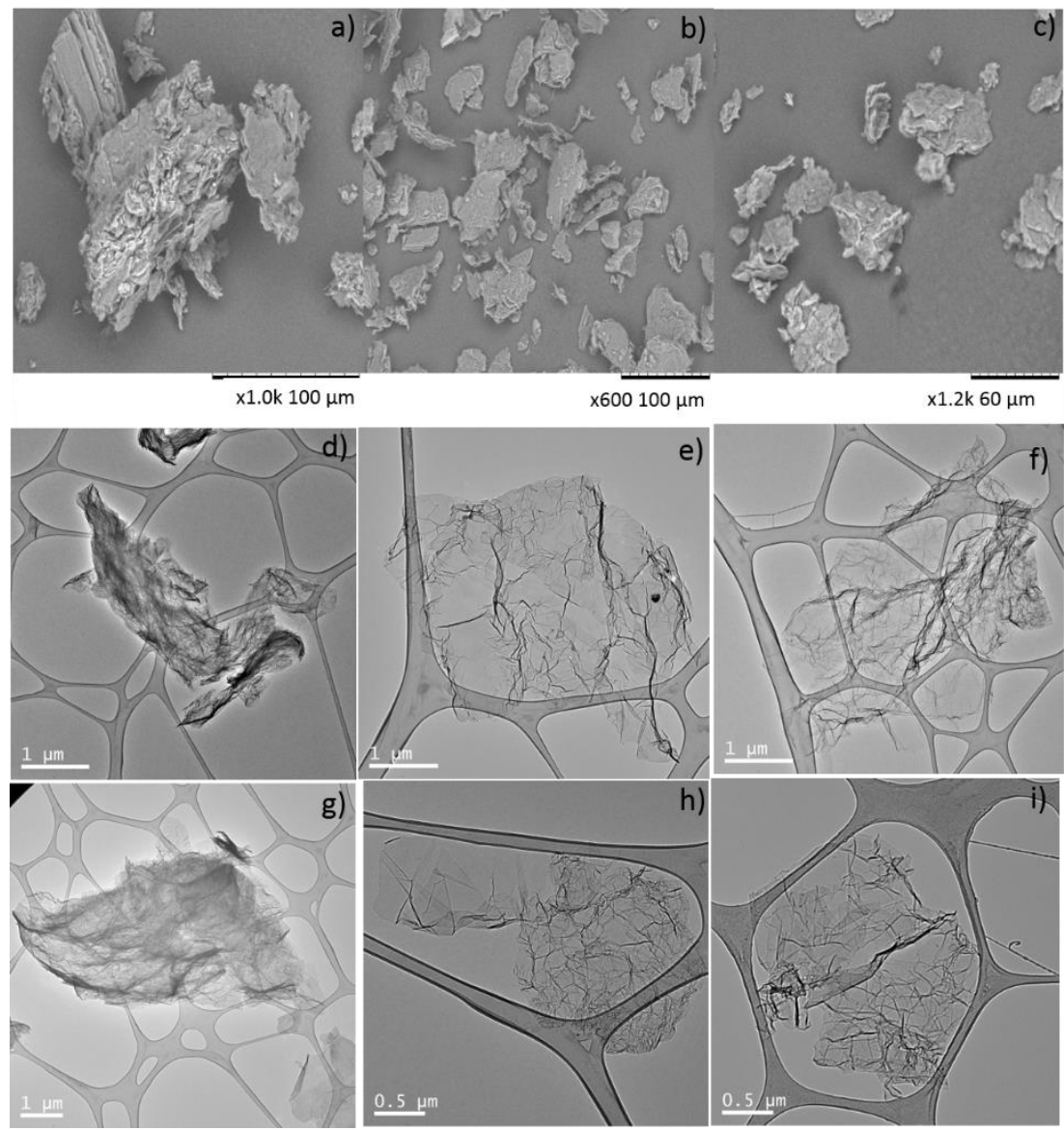

Figure 2. Representative SEM images of (a) $\mathrm{GO}_{10}$, (b) $\mathrm{GO}_{100}$ and (c) $\mathrm{GO}_{325}$ samples. TEM micrographs for (d) $\mathrm{rGO}_{10}-3$, (e) $\mathrm{rGO}_{100}-3$, (f) $\mathrm{rGO}_{325}-3$, (g) $\mathrm{NrGO}_{10}-4$, (h) $\mathrm{NrGO}_{100}-4$ and (i) $\mathrm{NrGO}_{325}-4$ samples. NrGO: N-doped reduced graphene oxide, rGO: reduced graphene oxide.

Table 1. Interlayer distance $d_{(002)}$, estimated number of layers $\left(\mathrm{N}_{\mathrm{L}}\right), \mathrm{S}_{\mathrm{BET}}$, and $\mathrm{N}$ content $(\%)$ for $\mathrm{N}$ doped and non-doped reduced graphene oxide samples.

\begin{tabular}{|c|c|c|c|c|c|c|c|}
\hline $\mathrm{GO}_{\mathrm{m}}$ & Ramp & Atmosphere & Sample & $\mathrm{d}_{(002)}(\mathrm{nm})$ & $\mathbf{N}_{\mathbf{L}}{ }^{*}$ & $S_{\text {BET }}\left(m^{2} g^{-1}\right)$ & $\mathbf{N}(\%)$ \\
\hline \multirow[t]{5}{*}{$\mathrm{GO}_{325}$} & 1 & Inert & $\mathrm{rGO}_{325}-1$ & 0.35 & 13 & 767 & - \\
\hline & 2 & & $\mathrm{rGO}_{325}-2$ & 0.35 & 10 & 804 & - \\
\hline & 3 & & $\mathrm{rGO}_{325}-3$ & 0.34 & 12 & 867 & - \\
\hline & 4 & & $\mathrm{rGO}_{325}-4$ & 0.35 & 17 & 667 & - \\
\hline & 5 & & $\mathrm{rGO}_{325}-5$ & 0.36 & 26 & 866 & - \\
\hline $\mathrm{GO}_{100}$ & 3 & Inert & $\mathrm{rGO}_{100}-3$ & 0.35 & 10 & 778 & - \\
\hline $\mathrm{GO}_{10}$ & 3 & Inert & $\mathrm{rGO}_{10}-3$ & 0.34 & 18 & 505 & - \\
\hline \multirow[t]{5}{*}{$\mathrm{GO}_{325}$} & 1 & Ammonia & $\mathrm{NrGO}_{325}-1$ & 0.34 & 14 & 428 & 4.8 \\
\hline & 2 & & $\mathrm{NrGO}_{325}-2$ & 0.35 & 9 & 427 & 4.4 \\
\hline & 3 & & $\mathrm{NrGO}_{325-3}$ & 0.34 & 14 & 460 & 5.0 \\
\hline & 4 & & $\mathrm{NrGO}_{325}-4$ & 0.34 & 14 & 492 & 5.0 \\
\hline & 5 & & $\mathrm{NrGO}_{325}-5$ & 0.34 & 13 & 476 & 4.1 \\
\hline $\mathrm{GO}_{100}$ & 4 & Ammonia & $\mathrm{NrGO}_{100}-4$ & 0.35 & 10 & 420 & 3.8 \\
\hline $\mathrm{GO}_{10}$ & 4 & Ammonia & $\mathrm{NrGO}_{10}-4$ & 0.34 & 40 & 236 & 1.8 \\
\hline
\end{tabular}


The completion of the exfoliation process for the prepared graphene materials was investigated by XRD. Examination of the $\mathrm{rGO}_{325}-\mathrm{r}$ and $\mathrm{NrGO}_{325}-\mathrm{r}$ patterns (Figure S2 ESI) indicates that the selected exfoliation ramps, 3 (inert) and 4 (ammonia), conduce to a successful exfoliation of the GO325 sample since the characteristic diffraction peak at $2 \theta \sim 15^{\circ}$ of GO (see Figure 1 ) disappeared, suggesting a reduction of GO325 to $\mathrm{NrGO} 325$ and rGO325 samples [10]. In addition, the absence of reflections corresponding to crystalline graphite for $\mathrm{GO}_{325}-3$ and $\mathrm{NrGO}_{325}-4$ samples supports the adequacy of ramps 3 (inert) and 4 (ammonia). The greater or lesser success in the GO exfoliation process can be evaluated by the appearance or not of crystalline graphite reflections. Figure 3 shows the XRD patterns of $\mathrm{NrGO}_{m}-4$ and $\mathrm{rGO}_{\mathrm{m}}$-3. It can be seen that the exfoliation process was fully successful in inert atmosphere for all the GO and also in ammonia atmosphere, especially for the $\mathrm{GO}_{100}$ and $\mathrm{GO}_{325}$ samples, because only a small and broad peak appeared at $2 \theta$ slightly lower than $26^{\circ}$, corresponding to the graphite (002) reflection. This fact indicates that the sample contains some small restacking of graphene layers and the formation of a few-layer graphene structures. The intensity of this peak displays a progressive increase with the particle size of the GO starting material, showing a higher number of restacked layers $\left(\mathrm{rGO}_{10}>\mathrm{rGO}_{100} \geq \mathrm{rGO}_{325}\right)$. Particularly, the progressive association of the graphene sheets produced after blasting is favored under ammonia reactive conditions but without reaching the level typical for crystalline graphite. This tendency is coherent with the values of $S_{B E T}$. The average stacking number of graphene layers $\left(\mathrm{N}_{\mathrm{L}}\right)$ in the exfoliated samples was estimated by using the layer-to-layer distance $\left(\mathrm{d}_{(002)}\right)$ and the size of the crystallite measured from the width of the diffraction peak of the (002) reflection, using the Scherrer equation [12]. The $\mathrm{N}_{\mathrm{L}}$ calculated show higher values than the ones expected according to the $S_{\mathrm{BET}}$ obtained. This may be due to the fact that the XRD signal is strongly influenced by the thicker particles, because although these constitute a minor proportion in the total of the sample, they are the ones with the highest diffraction signal. The X-ray crystalline parameters are shown in Table 1.



Figure 3. XRD patterns of reduced graphene materials.

Some morphological evidences of the differences between $\mathrm{rGO}$ and $\mathrm{NrGO}$ were determined by TEM (Figure 2). The rGO TEM images exhibited the presence of winkled structures of graphene. The introduction of nitrogen in the graphitic structure - the NrGO samples-did not produce noticeable difference in the morphology of the graphene sheets. High resolution transmission electron microscopy (HRTEM) characterization further showed that $\mathrm{rGO}_{\mathrm{m}}-3$ and $\mathrm{NrGO}_{\mathrm{m}}-4$ samples consist of $5-12$ graphene layers (Figure S3).

The elemental analysis technique was used to determine the amount of nitrogen atoms in the graphene materials (see Table 1 for $\mathrm{N}$ wt \%). For the rGO sample, nitrogen was not found. The 
$\mathrm{NrGO}_{325}-4$ sample presents the higher $\mathrm{N}$ content among the NrGO samples with 5.0 wt \%, and a gradual decrease of the $\mathrm{N}$ content values was observed as the size of starting graphite increases. There are two explanations for this phenomenon. First, this tendency can be explained in terms of the higher degree of oxidation obtained in GO samples with smaller graphite particle sizes [38]. It is known that the oxygen functional groups in GO including carbonyl, carboxylic, lactone, and quinone groups are responsible for reacting with $\mathrm{NH}_{3}$ to form $\mathrm{C}-\mathrm{N}$ bonds, allowing the incorporation of $\mathrm{N}$ in the structure [34]. Thus, a smaller graphite particle size favors the formation of GO with a higher degree of oxidation, which could lead to higher $\mathrm{N}$ contents. Besides, the higher degree of exfoliation of small crystals also facilitates the contact of the ammonia with the oxygen groups in the basal plane of the sheets, leading to a better incorporation of $\mathrm{N}$ atoms.

XPS is a powerful technique to identify the chemical states of the surface species. It was used to analyze the surface of the different graphene materials from the characteristic XPS peaks corresponding to $\mathrm{C}, \mathrm{N}$, and $\mathrm{O}$ regions (Figure S4 ESI shows general XPS spectra). The results obtained from the analysis of the C1s, O1s, and N1s individual high-resolution spectra are shown in Table 2. The assignment of the components of the N1s, O1s, and C1s region is not straightforward. The value of binding energy observed for the different functional groups of these elements varies in the literature. It may be due to the specific environments of the atoms and the redistribution of electrons after the ionization of the sample [30,41-43]. Nitrogen peak deconvolution for the $\mathrm{NrGO}_{\mathrm{m}}-4$ samples (Figure 4) indicated the presence of four elementary peaks: pyridinic nitrogen (399.5-398.5 eV), pyrrolic nitrogen (400.8-399.8 eV), quaternary nitrogen (403.0-401.0 eV), and NOx groups (404.9-405.6 eV) [10,44-48]. XPS analysis indicated that about 3.2-3.4 at \% $\mathrm{N}$ was found in the surface of the graphene sheets after ammonia treatment. These values are lower than those corresponding to the bulk N\% content obtained by elemental analysis. This difference could be attributed to inhomogeneous nitrogen doping of the graphenic materials, since it was inferior at the surface analyzed by XPS. For rGO samples, the nitrogen peak was undetected. The percentage of pyridinic N species was slightly higher for the samples obtained from smaller sizes and quaternary nitrogen was higher for the samples obtained from bigger ones. The pyridinic nitrogen is the most basic among the different $\mathrm{N}$ species. Therefore, the basicity of carbon catalysts is related to the content of pyridinic groups $[48,49]$.

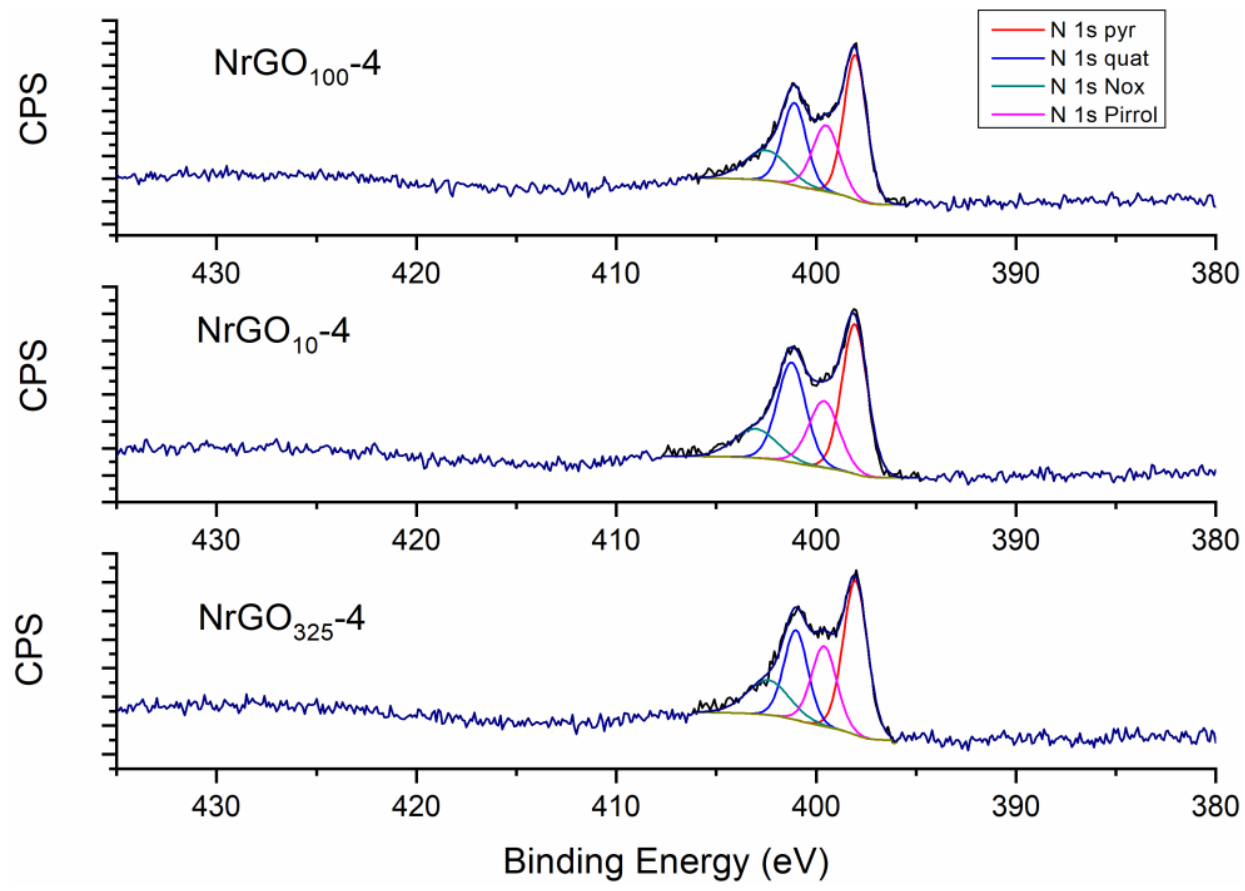

Figure 4. XPS spectra of the N 1s region for NrGO100-4, NrGO10-4, and NrGO325-4 samples. 
Table 2. XPS deconvolution results and $\mathrm{RAMAN} \mathrm{I}_{\mathrm{D}} / \mathrm{I}_{\mathrm{G}}$ ratio for $\mathrm{rGO}_{\mathrm{m}}-3$ and $\mathrm{NrGO}_{\mathrm{m}}-4$ samples.

\begin{tabular}{|c|c|c|c|c|c|c|c|c|c|c|c|}
\hline \multirow{2}{*}{ Sample } & \multirow{2}{*}{ O (at \%) } & \multirow{2}{*}{ N (at \%) } & \multicolumn{4}{|c|}{ O 1s } & \multicolumn{4}{|c|}{ N1s } & \multirow{2}{*}{$\mathbf{I}_{\mathrm{D}} / \mathbf{I}_{\mathrm{G}}$} \\
\hline & & & $\mathrm{C}-\mathrm{O}$ & $\mathrm{C}=\mathrm{O}$ & $\mathrm{COOH}$ & $\mathrm{H}_{2} \mathrm{O}$ & Pyr & Pyrr & Quat & Nox & \\
\hline $\mathrm{rGO}_{325}-3$ & 7.0 & - & 57.0 & 21.1 & 15.7 & 6.2 & - & - & - & - & 0.63 \\
\hline $\mathrm{rGO}_{100}-3$ & 7.0 & - & 63.1 & 17.0 & 13.7 & 6.3 & - & - & - & - & 0.39 \\
\hline $\mathrm{rGO}_{10}-3$ & 6.8 & - & 54.6 & 20.7 & 18.7 & 6.0 & - & - & - & - & 0.53 \\
\hline $\mathrm{NrGO}_{325^{-4}}$ & 4.1 & 3.4 & 54.7 & 23.5 & 17.6 & 4.2 & 40.0 & 21.7 & 22.7 & 15.6 & 0.75 \\
\hline $\mathrm{NrGO}_{100}-4$ & 3.6 & 3.3 & 54.2 & 21.2 & 18.9 & 5.7 & 39.5 & 21.7 & 23.6 & 15.3 & 0.63 \\
\hline $\mathrm{NrGO}_{10}-4$ & 3.6 & 3.2 & 56.2 & 17.4 & 18.7 & 7.6 & 38.5 & 20.5 & 28.5 & 12.4 & 0.58 \\
\hline
\end{tabular}

The C1s spectra was solved considering five components, which can be assigned to graphitic $\mathrm{sp}^{2}$ carbon atoms (284.6-285.1 eV), the C-O bonds present in alcohol or ether groups (286.3-287.0 eV), C=O functional groups (287.5-288.1 eV), carboxyl or ester groups (289.3-290 eV), and a fifth wide shake-up satellite peak representing the $\pi-\pi^{*}$ transitions of aromatic rings $(291.2-292.1 \mathrm{eV})[46,50]$.

Concerning O1s, the curve was fitted considering four contributions corresponding to carbonyl groups (531.1-531.8 eV), epoxide and hydroxyl groups (532.3-533.3 eV), carboxylic groups (534.0-534.4 eV), and chemisorbed $\mathrm{H}_{2} \mathrm{O}$ or oxygen (535.5-536.1 eV) [43,46,50-52]. The spectra analysis revealed that surface oxygen content varies from 3.6-4.1 at \% to 6.8-7.0 at \% for $\mathrm{N}$-doped and non-doped samples, respectively. The relatively small amount of oxygen with respect to that of carbon may be attributed to the process temperature. It is known that higher temperatures during the thermal treatment produce a decrease of the amount of oxygen functional groups [25]. The oxygen/carbon atomic ratios also confirm this, as can be seen in Table 2. The differences in these ratios for the various samples can be ascribed to an enhancement in oxidation degree from the original $\mathrm{GO}_{\mathrm{m}}$. For samples from raw graphite with smaller particle sizes, the oxidation degree of GO is higher. After the thermal treatment, the final content of oxygen is slightly higher for samples from graphite with a smaller particle size.

The point of zero charge (PZC) was used to assess the surface chemistry of the graphene materials [9], because the surface charge of carbon materials is directed by the type and population of functional groups and the $\mathrm{pH}$. The NrGO samples (Figure 5) show a PZC of 8.5-8.7, while rGO samples exhibit lower PZC values of 7.2-7.4. Therefore, the rGO samples have a practically neutral surface, while the NrGO surfaces are more basic. The incorporation of nitrogen atoms into the graphene structure means more electrons in comparison with carbon atoms and this fact favors the delocalization of p electrons in $\mathrm{N}$-doped samples, leading to changes in the hydrophobicity of the surface. This excess of electrons produces a higher basic strength of NrGO surfaces [47].

Raman spectroscopy is a very useful tool to evaluate the degree of disorder in the structure of graphene [8]. Figure 6 shows Raman spectra for $\mathrm{rGO}_{\mathrm{m}}-3$ and $\mathrm{NrGO}_{\mathrm{m}}-4$ samples. As Raman spectra at discrete spots cannot provide an overall picture in the case of non-uniform defects distributions in the sample, spectral mapping was used to acquire 25 points over a $50 \times 50 \mu \mathrm{m}^{2}$ area. Two main peaks corresponding to vibrations with E2g symmetry in the graphitic lattice ( $G$ band) at $1580 \mathrm{~cm}^{-1}$ and to graphite edges or structural defects (D bands) at $1345 \mathrm{~cm}^{-1}$ were observed. Another two featured peaks have been reported in previous studies. A band $D^{\prime}$ peak appears at $1625 \mathrm{~cm}^{-1}$ as a shoulder of the $\mathrm{G}$ band. It arises from alterations in the tension of $\mathrm{sp}^{2}$ carbon atoms in the lattice caused by the arrangement of the electronic cloud [50]. A second peak assigned as $2 \mathrm{D}$ (historically called $\mathrm{G}^{\prime}$ ) is always present at $2700 \mathrm{~cm}^{-1}$ in the spectra of graphene materials [40]. 



Figure 5. PZC for rGOm-3 and N-doped reduced graphene oxide (NrGOm-4) samples.
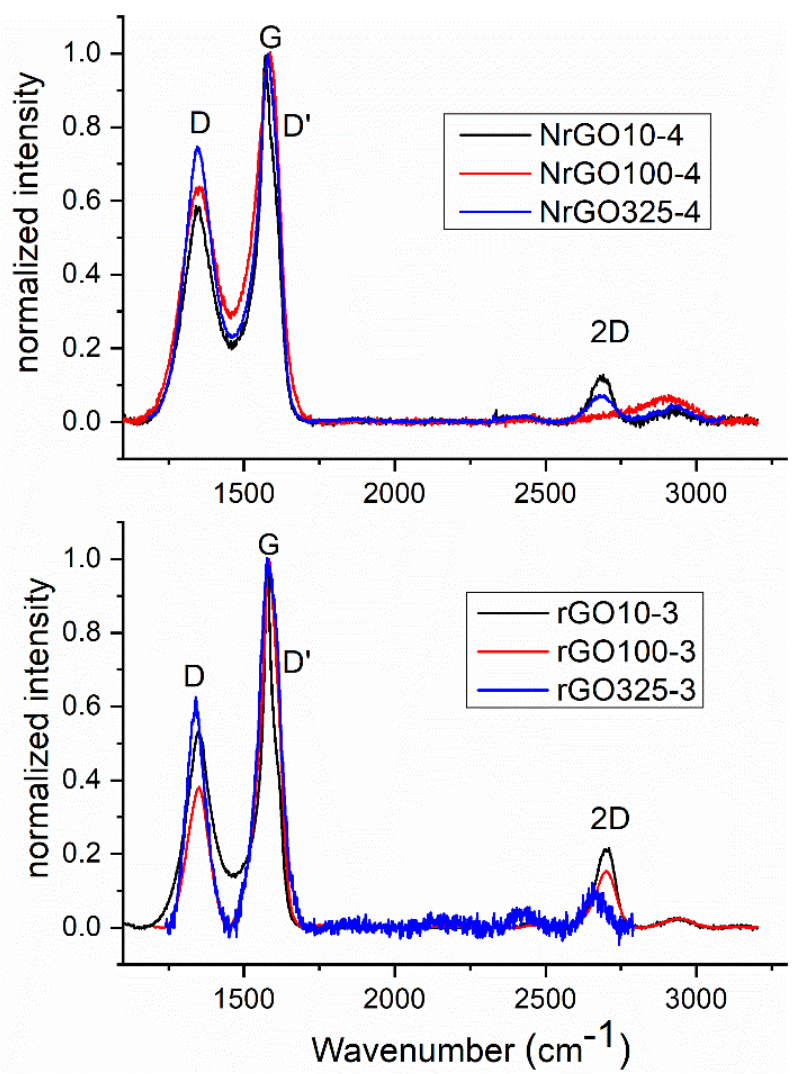

Figure 6. Raman spectra for $\mathrm{rGO}_{\mathrm{m}}-3$ and $\mathrm{NrGO}_{\mathrm{m}}-4$ samples.

The intensity ratio of the $\mathrm{D}$ and $\mathrm{G}$ bands $\left(\mathrm{I}_{\mathrm{D}} / \mathrm{I}_{\mathrm{G}}\right)$ can be used as a quantitative indicator of the amount of disorder or edges within the structure of the samples. $\mathrm{I}_{\mathrm{D}} / \mathrm{I}_{\mathrm{G}}$ ratios were calculated (Table 2 ). A comparison of $\mathrm{rGO}_{\mathrm{m}}$ samples with their $\mathrm{NrGO}_{\mathrm{m}}$ counterparts shows that the ratio increases when $\mathrm{N}$ 
is introduced in the reduced graphite oxide. In addition, an increase with $\mathrm{N}$ content in the $\mathrm{NrGO}_{\mathrm{m}}$ series is observed. This is due to a disruption of the symmetry of the lattice produced by the incorporation of heteroatoms into the graphitic structure. This effect has been described previously by Chen et al. [53]. They claimed that the introduction of $\mathrm{N}$ into the carbon lattice could produce distortions, transforming the graphitic region into an $\mathrm{sp}^{3}$ domain. From the Raman spectra, it can be observed that an increment in the $\mathrm{N}$ content leads to a shift of the $\mathrm{D}$ band to lower frequencies.

For a bulk graphite sample, the 2D band consists of two contributions. For single-layer graphene, the 2D band appears as a single sharp peak at the lower frequency (around $2690 \mathrm{~cm}^{-1}$ ). As the number of layers increases, the 2D band changes its shape, width, and position, and the $\mathrm{G}$ peak position shifts to lower frequencies [8]. A systematic study of the in-plane crystallite size was carried out in 1970 by Tuinstra and Koenig [54]. They found that the ratio of the $\mathrm{D}$ and $\mathrm{G}$ band intensities $\left(\mathrm{I}_{\mathrm{D}} / \mathrm{I}_{\mathrm{G}}\right)$ is inversely proportional to the in-plane crystallite sizes $\left(\mathrm{L}_{\mathrm{a}}\right)$. The crystallite sizes $\left(\mathrm{L}_{\mathrm{a}}\right)$ can be calculated from $\mathrm{L}_{\mathrm{a}}(\mathrm{nm})$ $=\left(2.4 \times 10^{-10}\right) \lambda^{4}\left(\mathrm{I}_{\mathrm{D}} / \mathrm{I}_{\mathrm{G}}\right)^{-1}\left(\lambda\right.$ being the Raman excitation wavelength) [55]. $\mathrm{L}_{\mathrm{a}}$ were $25.6-33.1 \mathrm{~nm}$ for NrGO samples and 30.5-49.3 nm for rGO samples; it is concluded that the crystallite size decreases with the presence of defects, and therefore the doping level. It is consistent with the bibliography [40], which point outs that since $\mathrm{L}_{\mathrm{a}}$ is the average interdefect distance, the introduction of nitrogen atoms accompanied by defects implies a smaller $\mathrm{L}_{\mathrm{a}}$.

The stability of the prepared graphenic materials in air atmosphere with the temperature was studied by thermal gravimetric analysis (Figure S5, ESI). Differential thermogravimetric profiles for $\mathrm{rGO}_{\mathrm{m}}-3$ samples show pronounced peaks near $598-642^{\circ} \mathrm{C}$ that could be attributed to a weight loss due to the oxidation of a graphitized carbon structure. In comparison, for $\mathrm{NrGO}_{\mathrm{m}}-4$ samples, this peak moved toward higher temperatures, showing oxidation temperatures between 663 and $671{ }^{\circ} \mathrm{C}$. These findings reveal that the presence of nitrogen in the NrGO samples rise the stability in air of the graphenic material, which is in agreement with previous results [33].

\subsection{ORR Electrocatalytic Activities}

To assess the electrocatalyst's properties toward ORR of the N-doped $\left(\mathrm{NrGO}_{325}-4, \mathrm{NrGO}_{100}-4\right.$, and $\left.\mathrm{NrGO}_{10}-4\right)$ and non-doped $\left(\mathrm{rGO}_{325}-3, \mathrm{rGO}_{100}-3\right.$, and $\left.\mathrm{rGO}_{10}-3\right)$ graphenic materials, a cyclic voltammetry study was initially performed in a $\mathrm{KOH}$ electrolyte $\left(0.1 \mathrm{~mol} \mathrm{dm}{ }^{-3}\right)$ saturated with $\mathrm{N}_{2}$ and $\mathrm{O}_{2}$. Figure $\mathrm{S} 6$ (ESI) shows the $\mathrm{CVs}$ in the $\mathrm{N}_{2}$ and $\mathrm{O}_{2}$ electrolytes for the six samples tested. In the presence of $\mathrm{N}_{2}$, no redox processes are detected, while in the electrolyte purged with $\mathrm{O}_{2}$, the six graphene materials studied showed an irreversible ORR peak with $0.74 \geq E_{\mathrm{pc}} \geq 0.72 \mathrm{~V}$ versus RHE. For comparison, the commercial $\mathrm{Pt} / \mathrm{C}(20 \mathrm{wt} \%)$ was also measured in the same experimental conditions toward ORR (Figure S7a, ESI), presenting analogous behavior to the graphene materials with $E_{\mathrm{pc}}=$ $0.88 \mathrm{~V}$ versus RHE.

Then, the electrocatalytic properties toward ORR were further studied by LSV with an RDE at several rotation speeds in $\mathrm{KOH}$ purged with $\mathrm{O}_{2}$. The LSVs of all graphene materials are presented in Figure 7, while those corresponding to $\mathrm{Pt} / \mathrm{C}$ can be seen in Figure S7b. All graphene materials presented a linear relationship between $j_{\mathrm{L}}$ and rotation speed, suggesting that the electron transfer reaction is diffusion limited. The LSVs show three different regions: for $E$ higher than $\approx 0.80 \mathrm{~V}$, the process is kinetically controlled; potential values between $\approx 0.80 \mathrm{~V}$ and $\approx 0.50 \mathrm{~V}$ indicate the mixed kinetic-diffusion region, and for $E \leq 0.50 \mathrm{~V}$, the process is controlled by $\mathrm{O}_{2}$ diffusion. 

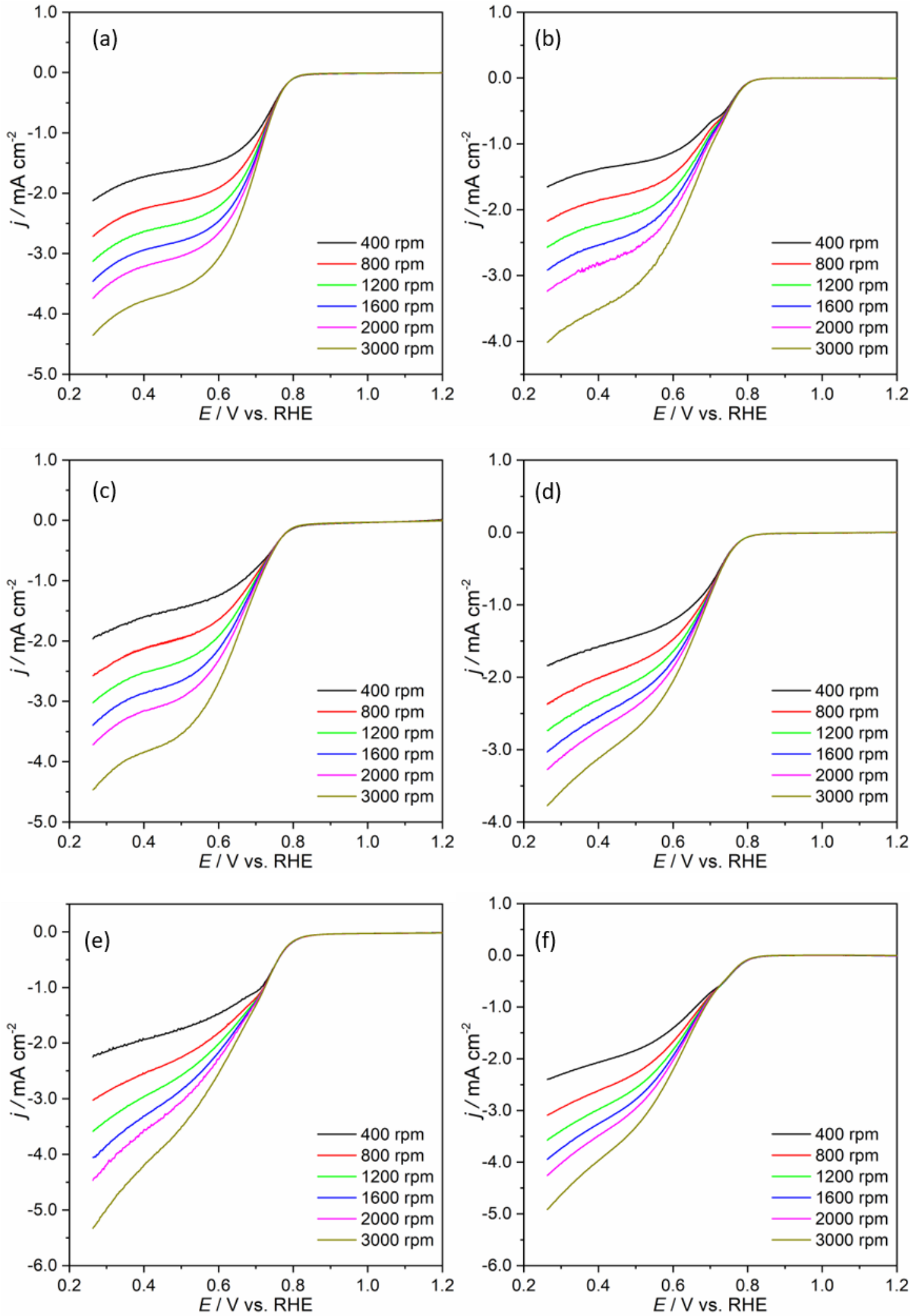

Figure 7. Oxygen reduction reaction (ORR) polarization curves of $\mathrm{rGO}_{10}-3(\mathbf{a}), \mathrm{rGO}_{100}-3(\mathbf{b}), \mathrm{rGO}_{325}-3$ (c), $\mathrm{NrGO}_{10}-4$ (d), $\mathrm{NrGO}_{100}-4(\mathbf{e})$, and $\mathrm{NrGO}_{325}-4$ (f) modified electrodes at different rotation rates in $\mathrm{KOH}$ purged with $\mathrm{O}_{2}$ at $0.005 \mathrm{~V} \mathrm{~s}^{-1}$.

Table 3 shows comparisons of the obtained $E_{\text {onset }}$ and $j_{\mathrm{L}, 0.26 \mathrm{~V}, 1600 \mathrm{rpm}}$ values for the N-doped and non-doped graphene materials at $1600 \mathrm{rpm}$. All the ECs showed similar onset potentials $\left(0.82 \geq E_{\text {onset }}\right.$ 
$\geq 0.79 \mathrm{~V}$ versus RHE), but higher $j_{L}, 0.26 \mathrm{~V}, 1600 \mathrm{rpm}$ values were obtained for the $\mathrm{N}$-doped materials. For the non-doped graphene materials, these values varied between -2.92 and $-3.46 \mathrm{~mA} \mathrm{~cm}^{-2}$, while for the $\mathrm{N}$-doped materials, they varied between -3.03 and $-4.05 \mathrm{~mA} \mathrm{~cm}{ }^{-2}$. The $\mathrm{NrGO}_{325}-4$ electrocatalyst showed the most promising result of all the prepared graphenic materials with the more positive $E_{\text {onset }}$ of $0.82 \mathrm{~V}$ versus RHE ( $0.12 \mathrm{~V}$ more negative than $\mathrm{Pt} / \mathrm{C})$ and the higher $j_{\mathrm{L}}, 0.26 \mathrm{~V}, 1600 \mathrm{rpm}$ of $-4.05 \mathrm{~mA} \mathrm{~cm}^{-2}$. The introduction of nitrogen species led to an improvement in the ORR properties, which is in agreement with several works that have reported the enhancement of ORR electrocatalytic activity after the N-doping of carbon materials [56,57]. Furthermore, comparing the results for the non-doped graphenic materials, it seems that the particle size of the starting graphite does not have a clear direct relationship with their ORR properties, unlike is observed for the N-doped materials. For the latter, as the particle size of the starting graphite decreased, there was an improvement of the ORR features (more positive $E_{\text {onset }}$ values and higher $j_{\mathrm{L}}$ ), and this is a consequence of the higher degree of oxidation that favored the incorporation of increased amounts of nitrogen, leading to higher possible active sites for oxygen reduction. This is supported by the elemental analysis results where the percentages of nitrogen obtained were $5.0 \%, 3.8 \%$, and $1.8 \%$ for $\mathrm{NrGO}_{325}-4, \mathrm{NrGO}_{100}-4$, and $\mathrm{NrGO}_{10}-4$, respectively.

Table 3. Relevant ORR parameters for commercial $\mathrm{Pt} / \mathrm{C}$ and activated carbons prepared.

\begin{tabular}{ccccc}
\hline Sample & $\boldsymbol{E}_{\text {onset vs. RHE }}$ & $j_{\mathbf{L}}\left(\mathbf{m A ~ c m} \mathbf{~ c}^{-\mathbf{2}}\right)$ & $\tilde{\mathbf{n}}_{\mathbf{O} 2}$ & Tafel Slopes $_{\left(\mathbf{m V ~} \mathbf{~ d e c}^{-\mathbf{1}}\right)^{*}}$ \\
\hline $\mathrm{Pt} / \mathrm{C}(20 \mathrm{wt} \%)$ & 0.94 & -4.70 & 4.0 & 89 \\
$\mathrm{rGO}_{325}-3$ & 0.81 & -3.40 & 2.6 & 98 \\
$\mathrm{rGO}_{100}-3$ & 0.80 & -2.92 & 2.2 & 48 \\
$\mathrm{rGO}_{10}-3$ & 0.80 & -3.46 & 3.1 & 65 \\
$\mathrm{NrGO}_{325}-4$ & 0.82 & -4.05 & 3.9 & 62 \\
$\mathrm{NrGO}_{100}-4$ & 0.80 & -3.94 & 3.3 & 78 \\
$\mathrm{NrGO}_{10}-4$ & 0.79 & -3.03 & 3.0 & 79 \\
\hline
\end{tabular}

* normalized by the mass of catalysts

Then, the ORR kinetics at different potentials were assessed with the Koutecky-Levich (K-L) plots obtained with the application of the K-L equation to the LSVs (in Figure 7) at rotation speeds in the range of 400 to $3000 \mathrm{rpm}$. The K-L plots of the graphene materials are presented in Figure S8, and those corresponding to $\mathrm{Pt} / \mathrm{C}$ are shown in Figure S7c. For the graphene materials, the $j^{-1}$ increases with increasing $\omega^{-1 / 2}$, which suggests a first-order electrocatalytic oxygen reduction with respect to the concentration of oxygen dissolved. Additionally, all the K-L plots of the non-doped materials show different slopes, suggesting that $\tilde{n}_{\mathrm{O} 2}$ depends on the applied potential, while for the N-doped ones, the differences are less significant. This suggests that in this case, $\mathrm{n}_{\mathrm{O} 2}$ is less dependent on the potential. The ORR process in alkaline medium can proceed by two pathways: a direct one involving one step (Equation 2) or an indirect one involving two steps (Equation 3 and 4) [reference 2 in ESI].

$$
\begin{gathered}
\mathrm{O}_{2}+\mathrm{H}_{2} \mathrm{O}+4 \mathrm{e}^{-} \rightarrow \mathrm{HO}^{-} \\
\mathrm{O}_{2}+\mathrm{H}_{2} \mathrm{O}+2 \mathrm{e}^{-} \rightarrow \mathrm{HO}_{2}^{-}+\mathrm{HO}^{-} \\
\mathrm{HO}_{2}^{-}+\mathrm{H}_{2} \mathrm{O}+2 \mathrm{e}^{-} \rightarrow 3 \mathrm{HO}^{-}
\end{gathered}
$$

The mean $n_{\mathrm{O} 2}\left(\tilde{n}_{\mathrm{O} 2}\right)$ values estimated from Equation 3 in ESI are depicted in Table 3, and Figure 8a shows the changes of $n_{\mathrm{O} 2}$ with the applied potential. For the non-doped materials, as the potential decreases from 0.46 to $0.26 \mathrm{~V}$ versus $\mathrm{RHE}$, there is an increase in $\mathrm{n}_{\mathrm{O} 2}$ values with $\Delta \mathrm{E}$ values of $1.0,0.53$, and $0.71 \mathrm{~V}$ for $\mathrm{rGO}_{10}-3, \mathrm{rGO}_{100}-3$, and $\mathrm{rGO}_{325}-3$, respectively. The variation for the $\mathrm{N}$-doped materials is less significant with $0.40 \geq \Delta \mathrm{E} \geq 0.22 \mathrm{~V}$ versus $\mathrm{RHE}$. The results of mean $\mathrm{n}_{\mathrm{O} 2}$ values obtained suggest that $\mathrm{rGO}_{100^{-}} 3$ and $\mathrm{rGO}_{325}-3$ proceed through the indirect pathway, while $\mathrm{rGO}_{10}-3, \mathrm{NrGO}_{10}-4$, and $\mathrm{NrGO}_{100}-4$ seem to proceed through a mixed mechanism, similar to $\tilde{n}_{\mathrm{O} 2} \approx 3$. This behavior has already been reported for other $\mathrm{N}$-doped structures [58]. On the other hand, for the $\mathrm{NrGO}_{325}-4$, a one-step 
four-electron transfer mechanism seems to be the leading process, since $\tilde{n}_{\mathrm{O} 2}=3.9$. This value is equal to the one obtained for $\mathrm{Pt} / \mathrm{C}$. Additionally, this result is better than that obtained for the other N-doped carbon nanotubes and graphene $[32,59,60]$.
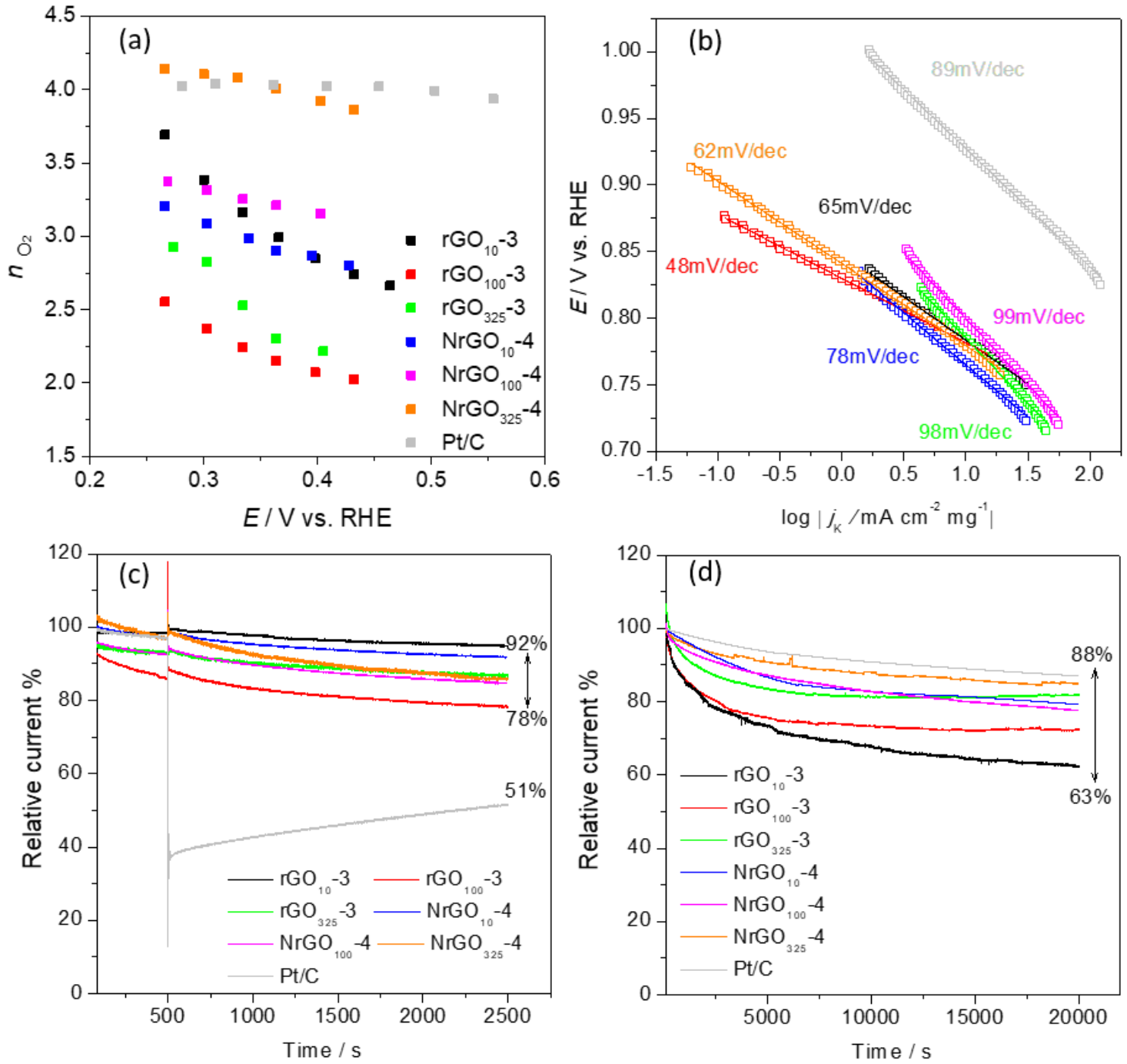

Figure 8. $n_{\mathrm{O} 2}$ at several potential values (a); ORR Tafel plots (b); chronoamperograms in $\mathrm{O}_{2}$-saturated $\mathrm{KOH}$ electrolyte at $1600 \mathrm{rpm}$ and $E=0.50 \mathrm{~V}$ vs. reversible hydrogen electrode (RHE), with the addition of methanol $\left(0.5 \mathrm{~mol} \mathrm{dm}^{-3}\right)$ at $t=500 \mathrm{~s}(\mathbf{c})$ and without for $20000 \mathrm{~s}(\mathbf{d})$.

The better ORR performances $\left(j_{\mathrm{L}}\right.$ and $\left.\tilde{n}_{\mathrm{O} 2}\right)$ of the $\mathrm{N}$-doped materials in comparison with the non-doped may be related to the presence of nitrogen as explained before, while the differences between the three $\mathrm{N}$-doped materials to the percentages and types of $\mathrm{N}$ species found could also be related to the particle size of the starting graphite. As discussed above in Section 3.1, usually a higher degree of oxidation is obtained in GO samples with smaller graphite particle size, and on the other hand, oxygen functional groups are responsible for reacting with $\mathrm{NH}_{3}$, leading to the incorporation of nitrogen in the structure, which will favor ORR. Elemental analysis showed that $\mathrm{NrGO}_{325}-4, \mathrm{NrGO}_{100}-4$, and $\mathrm{NrGO}_{10}-4$ presented $5.0 \%, 3.8 \%$, and $1.8 \%$ of $\mathrm{N}$, respectively, whereas the XPS results indicated percentages of $3.4 \%, 3.3 \%$, and $3.2 \%$. The $\mathrm{NrGO}_{325}-4$ sample presents a higher $\mathrm{N} \%$ at the surface and has also a higher percentage of pyridinic nitrogen. The latest have been reported to work as ORR electrocatalytic sites due to the electron donated to the conjugated $\pi$-bond of graphene and to the lone pair of electrons they have $[61,62]$. 
To confirm the excellent result obtained for $\mathrm{NrGO}_{325}-4$, RRDE tests were performed. The $j$ values obtained at the disk and ring are depicted in Figure S9a. For comparison, the $\mathrm{Pt} / \mathrm{C}$ data were also included. Equation (1) was used to estimate the percentage of $\mathrm{H}_{2} \mathrm{O}_{2}$ produced, and the results are presented in Figure $\mathrm{S} 9 \mathrm{~b}$ at several potential values. The $\mathrm{NrGO}_{325}-4$ electrocatalyst presented a low percentage of $\mathrm{H}_{2} \mathrm{O}_{2}(\approx 15 \%)$, which is in accordance with the high $\tilde{n}_{\mathrm{O} 2}$ value $\left(\tilde{n}_{\mathrm{O} 2}=3.9\right)$, while a value of $3 \%$ was obtained for $\mathrm{Pt} / \mathrm{C}$.

Tafel plots (Figure 8b) were obtained from LSV data in Figures S8 and S7b in KOH electrolyte purged with $\mathrm{O}_{2}$ at $1600 \mathrm{rpm}$. The Tafel slopes obtained between $E=1.00$ to $0.70 \mathrm{~V}$ versus RHE were 65 , $48,98,78,99,62$, and $89 \mathrm{mv} \mathrm{dec}^{-1}$ for $\mathrm{rGO}_{10}-3, \mathrm{rGO}_{100}-3, \mathrm{rGO}_{325}-3, \mathrm{NrGO}_{10}-4, \mathrm{NrGO}_{100}-4, \mathrm{NrGO}_{325}-4$, and $\mathrm{Pt} / \mathrm{C}$, respectively. All electrocatalysts except for $\mathrm{rGO}_{325}-3$ and $\mathrm{NrGO}_{100}-4$ presented Tafel slopes lower than those obtained for $\mathrm{Pt} / \mathrm{C}$, which suggests that the graphene materials can easily adsorb $\mathrm{O}_{2}$ onto their surface and activate it, promoting a robust electrocatalytic activity toward ORR. The different Tafel slopes obtained for $\mathrm{rGO}_{325}-3$ and $\mathrm{NrGO}_{100}-4$ are most likely associated to fluctuations in the oxygenated intermediates adsorption strength or to an incomplete electrocatalyst, which is used as a consequence of mass transport losses $[63,64]$. It is recognized that the intermediates adsorption strength is dependent on the physical properties and on the chemical nature of the selected electrocatalyst, which rules the determining step rate. For these two electrocatalysts, the first discharge step upon the consumption of the $\mathrm{MOOH}$ with a high coverage of $\mathrm{MOO}^{-}$is the rate-determining step, whereas for the remaining electrocatalysts, the conversion of $\mathrm{MOO}^{-}$to $\mathrm{MOOH}$ rules the overall reaction rate (where $\mathrm{M}$ stands for an empty site on the electrocatalyst surface) [63].

Tolerance to methanol crossover is another parameter that is usually evaluated because in fuels cells run on methanol, this can be a problem, as the performance of the cathode can be drastically reduced if the catalyst in sensitive to methanol. Therefore, to evaluate this parameter, chronoamperometric tests were performed in a $\mathrm{KOH}$ electrolyte purged with oxygen for $2500 \mathrm{~s}$, to which $0.5 \mathrm{~mol} \mathrm{dm}{ }^{-3}$ of methanol were added at $t=500 \mathrm{~s}$ (Figure $8 \mathrm{c}$ ). The presence of methanol led to an impressive decrease $(\approx 49 \%)$ of $\mathrm{Pt} / \mathrm{C}$ current. Oppositely, the graphene materials are much more stable and less sensible to methanol with current retentions between $78 \%$ and $92 \%$ suggesting higher selectivity toward oxygen reduction.

The EC stability is also of extreme importance. So, this was evaluated, for all graphene materials, using chronoamperometric runs in $\mathrm{KOH}$ electrolyte (in $\mathrm{O}_{2}$ ) for 20,000 s applying a potential of $E=0.50$ $\mathrm{V}$ versus RHE at $1600 \mathrm{rpm}$. The results obtained for $\mathrm{Pt} / \mathrm{C}$ and all graphenic materials are presented in Figure $8 \mathrm{~d}$. The best result was observed for $\mathrm{Pt} / \mathrm{C}$ with a current retention of $88 \%$. The $\mathrm{NrGO}_{325}-4$ electrocatalyst showed the best result from all the graphene materials with a current retention of $85 \%$, which is only 3\% less than Pt/C. For the other ECs, the current retention percentages were $63 \%, 72 \%$, $82 \%, 80 \%$, and $78 \%$ for $\mathrm{rGO}_{10}-3, \mathrm{rGO}_{100}-3, \mathrm{rGO}_{325}-3, \mathrm{NrGO}_{10}-4$, and $\mathrm{NrGO}_{100}-4$, respectively. The best performance of the $\mathrm{NrGO}_{325}-4$ electrocatalyst can be ascribed to the combination of two features, the $\mathrm{N}$-doping and the smaller particle size of the starting graphite.

\section{Conclusions}

In this paper, we report a viable method for the synthesis of graphene materials and nitrogen-doped reduced graphene oxide derivatives with enhanced properties. These are based on the chemical oxidation of graphite flakes with different particle sizes and selecting the experimental conditions used during the subsequent thermal exfoliation process.

The characterization results suggest that the starting particle size and thermal conditions applied during the exfoliation treatment remarkably affect the final surface properties of the prepared materials. The results point out that smaller particle sizes lead to higher surface areas. We achieved surface areas of $867 \mathrm{~m}^{2} \mathrm{~g}^{-1}$ for rGO. For NrGO samples obtained from graphite 10, 100, and 325, we observed BET surface areas of 236,420 , and $492 \mathrm{~m}^{2} \mathrm{~g}^{-1}$ respectively, which may provide a new way to control the surface area of $\mathrm{N}$-doped graphene.

The use of different reduction atmosphere $\left(\mathrm{NH}_{3}\right.$ versus inert) allow to successfully introduce nitrogen within the graphenic structure, enhancing the electronic properties and basicity of the doped 
materials. For the N-doped samples, the amount of nitrogen introduced and surface areas could be also tailored.

As a result of their tailored enhanced properties, these optimized NrGO and rGO samples were successfully applied as ORR electrocatalysts. The NrGO samples showed better ORR performance in alkaline medium with onset potentials ranging from 0.79 and $0.82 \mathrm{~V}$ versus RHE, low Tafel slopes $\left(62-99 \mathrm{mV} \mathrm{dec}^{-1}\right)$, and good $j_{\mathrm{L}}$ values $\left(-3.03--4.05 \mathrm{~mA} \mathrm{~cm}{ }^{-2}\right)$. The better performance of $\mathrm{NrGO}_{325}-4$ was attributed not only to the higher content of nitrogen but also to the smaller particle size of the starting material. Moreover, all the graphene materials presented good durability/stability and very low sensitivity to methanol. This work has led to a new class of metal-free ORR electrocatalysts with good efficiency and stability.

Supplementary Materials: The following are available online at http://www.mdpi.com/2079-4991/9/12/1761/s1, Experimental details; Figure $\mathrm{S} 1$ displays $\mathrm{N}_{2}$ adsorption-desorption isotherm for all samples; Figure $\mathrm{S} 2$ contains XRD spectra for rGO and NrGO samples; Figure S3 contains TEM images of the different graphene materials; Figure $\mathrm{S} 4$ shows survey XPS for $\mathrm{rGO}_{\mathrm{m}}-2$ and $\mathrm{NrGO}_{\mathrm{m}}-5$ samples; Figure $\mathrm{S} 5$ contains TGA for graphene materials; Figure $\mathrm{S} 6$ contains the $\mathrm{CVs}$ of $\mathrm{rGO}_{\mathrm{m}}-3$ and $\mathrm{NrGO}_{\mathrm{m}}-4$ modified electrodes in $\mathrm{N}_{2}$-saturated and $\mathrm{O}_{2}$-saturated $0.1 \mathrm{~mol}$ $\mathrm{dm}^{-3} \mathrm{KOH}$ solution; Figure S7 contains CVs, LSVs, and K-L plots for Pt/C; Figure S8 contains the ORR polarization curves of $\mathrm{rGO}_{\mathrm{m}}-3$ and $\mathrm{NrGO}_{\mathrm{m}}-4$ modified electrodes at different rotation rates in $\mathrm{O}_{2}$-saturated solution; Figure $\mathrm{S} 9$ contains LSVs recorded with RRDE and the estimated percentage of $\mathrm{H}_{2} \mathrm{O}_{2}$ formed for $\mathrm{Pt} / \mathrm{C}$ and $\mathrm{NrGO}_{325}-4$.

Author Contributions: A.G.-R. and I.R.-R. conceived and designed the experiments; C.S.R.-B. carried out the synthetic experiments; D.M.F. and C.F. conducted the electrocatalytic measurements; E.V.-A. performed the Raman characterization; D.M.F. and I.R.-R. wrote the original draft manuscript; and all the authors discussed the results and contributed to the manuscript.

Funding: This research was supported by the Spanish Agencia Estatal de Investigación (AEI) under projects CTQ-2017-89443-C3-1-R and CTQ-2017-89443-C3-3-R. C.S.R.B. gratefully acknowledges financial support from Spanish Ministerio de Educacion, Cultura y Deporte, Grant N ${ }^{\circ}$ FPU15/01838. D.M.F. also thanks Project UNIRCELL - POCI-01-0145-FEDER-016422 funded by European Structural and Investment Funds (FEEI) through - Programa operacional Competitividade e Internacionalização - COMPETE2020 and by national funds through FCT Fundação para a Ciência e a Tecnologia, I.P.

Conflicts of Interest: The authors declare no conflict of interest.

\section{References}

1. Geim, A.K.; Novoselov, K.S. The Rise of Graphene. Nat. Mater. 2007, 6, 183-191. [CrossRef] [PubMed]

2. Stoller, M.D.; Park, S.; Zhu, Y.; An, J.; Ruoff, R.S. Graphene-Based Ultracapacitors. Nano Lett. 2008, 8, 3498-3502. [CrossRef] [PubMed]

3. Sun, Y.; Wu, Q.; Shi, G. Graphene based new energy materials. Energy Environ. Sci. 2011, 4, 1113-1132. [CrossRef]

4. Raccichini, R.; Varzi, A.; Passerini, S.; Scrosati, B. The role of graphene for electrochemical energy storage. Nat. Mater. 2015, 14, 271-279. [CrossRef] [PubMed]

5. Bonaccorso, F.; Colombo, L.; Yu, G.; Stoller, M.; Tozzini, V.; Ferrari, A.C.; Ruoff, R.S.; Pellegrini, V. Graphene, Related Two-Dimensional Crystals, and Hybrid Systems for Energy Conversion and Storage. Science 2015, 347, 1246501. [CrossRef]

6. Weiss, N.O.; Zhou, H.; Liao, L.; Liu, Y.; Jiang, S.; Huang, Y.; Duan, X. Graphene: An Emerging Electronic Material. Adv. Mater. 2012, 24, 5782-5825. [CrossRef]

7. Soldano, C.; Mahmood, A.; Dujardin, E. Production, Properties and Potential of Graphene. Carbon 2010, 48, 2127-2150. [CrossRef]

8. Machado, B.F.; Serp, P. Graphene-Based Materials for Catalysis. Catal. Sci. Technol. 2012, 2, 54-75. [CrossRef]

9. Serp, P.; Figueiredo, J.L. Carbon Materials for Catalysis; John Wiley \& Sons, Inc: Hoboken, NJ, USA, 2008.

10. Asedegbega-Nieto, E.; Perez-Cadenas, M.; Morales, M.V.; Bachiller-Baeza, B.; Gallegos-Suarez, E.; Rodriguez-Ramos, I.; Guerrero-Ruiz, A. High Nitrogen Doped Graphenes and their Applicability as Basic Catalysts. Diam. Relat. Mater. 2014, 44, 26-32. [CrossRef]

11. Castillejos-Lopez, E.; Bachiller-Baeza, B.; Asedegbega-Nieto, E.; Guerrero-Ruiz, A.; Rodriguez-Ramos, I. Selective 1,3-butadiene Hydrogenation by Gold Nanoparticles Deposited \& Precipitated onto Nano-Carbon Materials. RSC Adv. 2015, 5, 81583-81598. 
12. Geng, D.; Yang, S.; Zhang, Y.; Yang, J.; Liu, J.; Li, R.; Sham, T.-K.; Sun, X.; Ye, S.; Knights, S. Nitrogen doping effects on the structure of graphene. Appl. Surf. Sci. 2011, 257, 9193-9198. [CrossRef]

13. Novoselov, K.S.; Geim, A.K.; Morozov, S.V.; Jiang, D.; Zhang, Y.; Dubonos, S.V.; Grigorieva, I.V.; Firsov, A.A. Electric Field Effect in Atomically Thin Carbon Films. Science 2004, 306, 666-669. [CrossRef] [PubMed]

14. Kim, K.S.; Zhao, Y.; Jang, H.; Lee, S.Y.; Kim, J.M.; Kim, K.S.; Ahn, J.-H.; Kim, P.; Choi, J.-Y.; Hong, B.H. Large-Scale Pattern Growth of Graphene Films for Stretchable Transparent Electrodes. Nature 2009, 457, 706-710. [CrossRef] [PubMed]

15. Berger, C.; Song, Z.; Li, X.; Wu, X.; Brown, N.; Naud, C.; Mayou, D.; Li, T.; Hass, J.; Marchenkov, A.N.; et al. Electronic Confinement and Coherence in Patterned Epitaxial Graphene. Science 2006, 312, 1191-1196. [CrossRef] [PubMed]

16. Hummers, W.S.; Offeman, R.E. Preparation of Graphitic Oxide. J. Am. Chem. Soc. 1958, 80, 1339. [CrossRef]

17. Brodie, B.C. On the Atomic Weight of Graphite. Philos. Trans. R. Soc. 1859, 149, 249-259.

18. Stankovich, S.; Dikin, D.A.; Piner, R.D.; Kohlhaas, K.A.; Kleinhammes, A.; Jia, Y.; Wu, Y.; Nguyen, S.T.; Ruoff, R.S. Synthesis of graphene-based nanosheets via chemical reduction of exfoliated graphite oxide. Carbon 2007, 45, 1558-1565. [CrossRef]

19. Shin, H.-J.; Kim, K.K.; Benayad, A.; Yoon, S.-M.; Park, H.K.; Jung, I.-S.; Jin, M.H.; Jeong, H.-K.; Kim, J.M.; Choi, J.-Y.; et al. Efficient Reduction of Graphite Oxide by Sodium Borohydride and Its Effect on Electrical Conductance. Adv. Funct. Mater. 2009, 19, 1987-1992. [CrossRef]

20. Zhou, M.; Wang, Y.; Zhai, Y.; Zhai, J.; Ren, W.; Wang, F.; Dong, S. Controlled Synthesis of Large-Area and Patterned Electrochemically Reduced Graphene Oxide Films. Chem. A Eur. J. 2009, 15, 6116-6120. [CrossRef]

21. Sundaram, R.S.; Gómez-Navarro, C.; Balasubramanian, K.; Burghard, M.; Kern, K. Electrochemical Modification of Graphene. Adv. Mater. 2008, 20, 3050-3053. [CrossRef]

22. Choucair, M.; Thordarson, P.; Stride, J.A. Gram-scale Production of Graphene Based on Solvothermal Synthesis and Sonication. Nat. Nanotechnol. 2009, 4, 30-33. [CrossRef] [PubMed]

23. Wang, H.; Robinson, J.T.; Li, X.; Dai, H. Solvothermal Reduction of Chemically Exfoliated Graphene Sheets. J. Am. Chem. Soc. 2009, 131, 9910-9911. [CrossRef] [PubMed]

24. McAllister, M.J.; Li, J.-L.; Adamson, D.H.; Schniepp, H.C.; Abdala, A.A.; Liu, J.; Herrera-Alonso, M.; Milius, D.L.; Car, R.; Prud'homme, R.K.; et al. Single Sheet Functionalized Graphene by Oxidation and Thermal Expansion of Graphite. Chem. Mater. 2007, 19, 4396-4404. [CrossRef]

25. Botas, C.; Álvarez, P.; Blanco, C.; Santamaría, R.; Granda, M.; Gutiérrez, M.D.; Rodriguez-Reinoso, F.; Menéndez, R. Critical Temperatures in the Synthesis of Graphene-like Materials by Thermal Exfoliation-Reduction of Graphite Oxide. Carbon 2013, 52, 476-485. [CrossRef]

26. Luo, Z.; Lim, S.; Tian, Z.; Shang, J.; Lai, L.; MacDonald, B.; Fu, C.; Shen, Z.; Yu, T.; Lin, J. Pyridinic N Doped Graphene: Synthesis, Electronic Structure, and Electrocatalytic Property. J. Mater. Chem. 2011, 21, 8038-8044. [CrossRef]

27. Reddy, A.L.M.; Srivastava, A.; Gowda, S.R.; Gullapalli, H.; Dubey, M.; Ajayan, P.M. Synthesis of Nitrogen-Doped Graphene Films for Lithium Battery Application. ACS Nano 2010, 4, 6337-6342. [CrossRef] [PubMed]

28. Jin, Z.; Yao, J.; Kittrell, C.; Tour, J.M. Large-Scale Growth and Characterizations of Nitrogen-Doped Monolayer Graphene Sheets. ACS Nano 2011, 5, 4112-4117. [CrossRef] [PubMed]

29. Panchakarla, L.S.; Subrahmanyam, K.S.; Saha, S.K.; Govindaraj, A.; Krishnamurthy, H.R.; Waghmare, U.V.; Rao, C.N.R. Synthesis, Structure and Properties of Boron and Nitrogen Doped Graphene. Adv. Mater. 2009, 21, 4726-4738. [CrossRef]

30. Wang, Y.; Shao, Y.; Matson, D.W.; Li, J.; Lin, Y. Nitrogen-Doped Graphene and Its Application in Electrochemical Biosensing. ACS Nano 2010, 4, 1790-1798. [CrossRef]

31. Lin, Z.; Song, M.; Ding, Y.; Liu, Y.; Wong, C. Facile Preparation of Nitrogen-Doped Graphene as a Metal-Free Catalyst for Oxygen Reduction Reaction. Phys. Chem. Chem. Phys. 2012, 14, 3381-3387. [CrossRef]

32. Sheng, Z.H.; Shao, L.; Chen, J.J.; Bao, W.J.; Wang, F.B.; Xia, X.H. Catalyst-Free Synthesis of Nitrogen-Doped Graphene Via Thermal Annealing Graphite Oxide with Melamine and its Excellent Electrocatalysis. ACS Nano 2011, 5, 4350-4358. [CrossRef] [PubMed]

33. Canty, R.; Gonzalez, E.; MacDonald, C.; Osswald, S.; Zea, H.; Luhrs, C.C. Reduction Expansion Synthesis as Strategy to Control Nitrogen Doping Level and Surface Area in Graphene. Materials 2015, 8, 7048-7058. [CrossRef] [PubMed] 
34. Li, X.; Wang, H.; Robinson, J.T.; Sanchez, H.; Diankov, G.; Dai, H. Simultaneous Nitrogen Doping and Reduction of Graphene Oxide. J. Am. Chem. Soc. 2009, 131, 15939-15944. [CrossRef] [PubMed]

35. Wu, Z.S.; Ren, W.; Gao, L.; Liu, B.; Jiang, C.; Cheng, H.M. Synthesis of High-Quality Graphene with a Pre-Determined Number of Layers. Carbon 2009, 47, 493-499. [CrossRef]

36. Paez, A.; Jesús, G.; Alvarez, P.; Granda, M.; Blanco, C.; Santamaria, P.; Blanco, R.; Fernandez, L.; Menendez, R.M.; Calle, F. Methods for Producing Graphene with Tunable Properties by a Multi-Step Thermal Reduction Process. WO 2016042099 A1, 18 September 2014.

37. Zhang, C.; Lv, W.; Xie, X.; Tang, D.; Liu, C.; Yang, Q.-H. Towards Low Temperature Thermal Exfoliation of Graphite Oxide for Graphene Production. Carbon 2013, 62, 11-24. [CrossRef]

38. Dao, T.D.; Jeong, H.M. Graphene Prepared by Thermal Reduction-Exfoliation of Graphite Oxide: Effect of Raw Graphite Particle Size on the Properties of Graphite Oxide and Graphene. Mater. Res. Bull. 2015, 70, 651-657. [CrossRef]

39. Muthuswamy, N.; Buan, M.E.M.; Walmsley, J.C.; Rønning, M. Evaluation of ORR Active Sites in Nitrogen-Doped Carbon Nanofibers by KOH Post Treatment. Catal. Today 2018, 301, 11-16. [CrossRef]

40. Wang, H.; Maiyalagan, T.; Wang, X. Review on Recent Progress in Nitrogen-Doped Graphene: Synthesis, Characterization, and Its Potential Applications. ACS Catal. 2012, 2, 781-794. [CrossRef]

41. Serp, P.; Machado, B.F. Nanostructured Carbon Materials for Catalysis, Royal Society of Chemistry; Royal Society of Chemistry: Cambridge, UK, 2015.

42. Wepasnick, K.A.; Smith, B.A.; Bitter, J.L.; Fairbrother, D.H. Chemical and Structural Characterization of Carbon Nanotube Surfaces. Anal. Bioanal. Chem. 2010, 396, 1003-1014. [CrossRef]

43. Desimoni, E.; Casella, G.I.; Morone, A.; Salvi, A.M. XPS Determination of Oxygen-Containing Functional Groups on Carbon-Fibre Surfaces and the Cleaning of these Surfaces. Surf. Interface Anal. 1990, 15, 627-634. [CrossRef]

44. Matter, P.H.; Zhang, L.; Ozkan, U.S. The Role of Nanostructure in Nitrogen-Containing Carbon Catalysts for the Oxygen Reduction Reaction. J. Catal. 2006, 239, 83-96. [CrossRef]

45. Pels, J.R.; Kapteijn, F.; Moulijn, J.A.; Zhu, Q.; Thomas, K.M. Evolution of Nitrogen Functionalities in Carbonaceous Materials during Pyrolysis. Carbon 1995, 33, 1641-1653. [CrossRef]

46. Biniak, S.; Szymański, G.; Siedlewski, J.; Światkoski, A. The Characterization of Activated Carbons with Oxygen and Nitrogen Surface Groups. Carbon 1997, 35, 1799-1810. [CrossRef]

47. Faba, L.; Criado, Y.A.; Gallegos-Suarez, E.; Pérez-Cadenas, M.; Díaz, E.; Rodriguez-Ramos, I.; Guerrero-Ruiz, A.; Ordóñez, S. Preparation of Nitrogen-Containing Carbon Nanotubes and Study of their Performance as Basic Catalysts. Appl. Catal. A Gen. 2013, 458, 155-161. [CrossRef]

48. García-García, F.R.; Álvarez-Rodríguez, J.; Rodriguez-Ramos, I.; Guerrero-Ruiz, A. The Use of Carbon Nanotubes with and without Nitrogen Doping as Support for Ruthenium Catalysts in the Ammonia Decomposition Reaction. Carbon 2010, 48, 267-276. [CrossRef]

49. van Dommele, S.; de Jong, K.P.; Bitter, J.H. Nitrogen-Containing Carbon Nanotubes as Solid Base Catalysts. Chem. Commun. 2006, 76, 4859-4861. [CrossRef]

50. Dongil, A.B.; Bachiller-Baeza, B.; Guerrero-Ruiz, A.; Rodríguez-Ramos, I.; Martínez-Alonso, A.; Tascón, J.M.D. Surface Chemical Modifications Induced on High Surface Area Graphite and Carbon Nanofibers Using Different Oxidation and Functionalization Treatments. J. Colloid Interface Sci. 2011, 355, 179-189. [CrossRef]

51. Figueiredo, J.L.; Pereira, M.F.R.; Freitas, M.M.A.; Órfão, J.J.M. Modification of the Surface Chemistry of Activated Carbons. Carbon 1999, 37, 1379-1389. [CrossRef]

52. Zielke, U.; Hüttinger, K.J.; Hoffman, W.P. Surface-Oxidized Carbon Fibers: I. Surface Structure and Chemistry. Carbon 1996, 34, 983-998. [CrossRef]

53. Chen, C.-M.; Zhang, Q.; Zhao, X.-C.; Zhang, B.; Kong, Q.-Q.; Yang, M.-G.; Yang, Q.-H.; Wang, M.-Z.; Yang, Y.-G.; Schlögl, R.; et al. Hierarchically Aminated Graphene Honeycombs for Electrochemical Capacitive Energy Storage. J. Mater. Chem. 2012, 22, 14076-14084. [CrossRef]

54. Tuinstra, F.; Koenig, J.L. Raman Spectrum of Graphite. J. Chem. Phys. 1970, 53, 1126-1130. [CrossRef]

55. Pimenta, M.A.; Dresselhaus, G.; Dresselhaus, M.S.; Cançado, L.G.; Jorio, A.; Saito, R. Studying Disorder in Graphite-Based Systems by Raman Spectroscopy. Phys. Chem. Chem. Phys. 2007, 9, 1276-1290. [CrossRef] [PubMed]

56. Qu, L.T.; Liu, Y.; Baek, J.B.; Dai, L.M. Nitrogen-Doped Graphene as Efficient Metal-Free Electrocatalyst for Oxygen Reduction in Fuel Cells. ACS Nano 2010, 4, 1321-1326. [CrossRef] [PubMed] 
57. Rocha, I.M.; Soares, O.G.P.; Fernandes, D.M.; Freire, C.; Figueiredo, J.L.; Pereira, M.F.R. N-Doped Carbon Nanotubes for the Oxygen Reduction Reaction in Alkaline Medium: Synergistic Relationship between Pyridinic and Quaternary Nitrogen. Chem. Sel. 2016, 1, 2522-2530. [CrossRef]

58. Kim, D.-W.; Lia, O.L.; Saito, N. Enhancement of ORR catalytic activity by multiple heteroatom-doped carbon materials. Phys. Chem. Chem. Phys. 2015, 17, 407-413. [CrossRef]

59. Fernandes, D.M.; Novais, H.C.; Bacsa, R.; Serp, P.; Bachiller-Baeza, B.; Rodríguez-Ramos, I.; Guerrero-Ruiz, A.; Freire, C. Polyoxotungstate@Carbon Nanocomposites as Oxygen Reduction Reaction (ORR) Electrocatalysts. Langmuir 2018, 34, 6376-6387. [CrossRef]

60. Li, H.; Liu, H.; Jong, Z.; Qu, W.; Geng, D.S.; Sun, X.; Wang, H. Nitrogen-doped carbon nanotubes with high activity for oxygen reduction in alkaline media. Int. J. Hydrogen Energy 2011, 36, 2258-2265. [CrossRef]

61. O'Hayre, R.; Cha, S.; Colella, W.; Prinz, F. Fuel Cell Fundamentals; John Wiley \& Sons: New York, NY, USA, 2005.

62. Subramanian, N.P.; Li, X.G.; Nallathambi, V.; Kumaraguru, S.P.; Colon-Mercado, H.; Wu, G.; Lee, J.W.; Popov, B.N. Nitrogen-Modified Carbon-based Catalysts for Oxygen Reduction Reaction in Polymer Electrolyte Membrane Fuel Cells. J. Power Sources 2009, 188, 38-44. [CrossRef]

63. Shinagawa, T.; Garcia-Escudero, A.T.; Takanabe, K. Insight on Tafel Slopes from a Microkinetic Analysis of Aqueous Electrocatalysis for Energy Conversion. Sci. Rep. 2015, 5, 13801. [CrossRef]

64. Chlistunoff, J. RRDE and Voltammetric Study of ORR on Pyrolyzed Fe/Polyaniline Catalyst. On the Origins of Variable Tafel Slopes. J. Phys. Chem. C 2011, 115, 6496-6507.

(C) 2019 by the authors. Licensee MDPI, Basel, Switzerland. This article is an open access article distributed under the terms and conditions of the Creative Commons Attribution (CC BY) license (http://creativecommons.org/licenses/by/4.0/). 